\title{
BILATERAL INTERNAL THORACIC ARTERY GRAFTING: LONG-TERM CLINICAL AND ANGIOGRAPHIC RESULTS OF IN SITU VERSUS Y GRAFTS
}

Antonio Maria Calafiore, MD

Marco Contini, MD

Giuseppe Vitolla, MD

Michele Di Mauro, MD

Valerio Mazzei, MD

Giovanni Teodori, MD

Gabriele Di Giammarco, MD
Background: We evaluated whether bilateral internal thoracic arteries provide the same long-term results when used as in situ grafts and as Y grafts.

Methods and results: From October 1991 to February 2000, 1818 patients had bilateral internal thoracic arteries used as in situ $(n=1378$, group A) or as Y grafts $(n=440$, group B). The number of anastomoses per patient and the number of bilateral internal thoracic artery anastomoses per patient were higher in group B $(3.1 \pm 0.9$ and $2.7 \pm 0.9)$ than in group A $(2.9 \pm 0.8$ and $2.2 \pm 0.6$ ) (both $P<.001$ ). The number of right internal thoracic artery anastomoses per patient rose from $1.0 \pm 0.3$ in group A to $1.4 \pm 0.6$ in group $B$ $(P<.001)$, and the number of sequential anastomoses per right internal thoracic artery graft rose from $4.1 \%$ to $34.3 \%(P<.001)$. Thirty-day mortality was $2.0 \%$ in group A versus $2.5 \%$ in group B $(P=$ not significant $)$. No difference in postoperative course was detected. Eight-year survivals were $95.8 \% \pm 2.7 \%$ in group A versus $94.8 \% \pm 4.0 \%$ in group B $(P=$ not significant), and event-free survivals were $95.2 \% \pm 2.9 \%$ in group A versus $93.6 \%$ $\pm 4.4 \%$ in group B ( $P=$ not significant). Early angiograms were obtained in 295 patients (945 anastomoses, 863 distal and 82 proximal Y grafts), 213 patients (611) in group A and 82 patients (334) in group B. Patency rate was $98.8 \%$ in group A and $96.0 \%$ in group $\mathrm{B}(P=$ not significant), whereas grade A patency rate was $97.2 \%$ in group $A$ and $96.4 \%$ in group $B(P=$ not significant). Late angiograms were obtained in 88 patients (25 in group A and 63 in group B) at a mean of $17.5 \pm 18.4$ months: patency rate was $100 \%$ in group A and 99.2 in group B ( $P=$ not significant), and grade A patency rate was $98.6 \%$ in group $\mathrm{A}$ and $98.8 \%$ in group $\mathrm{B}(P=$ not significant $)$. No $\mathrm{Y}$ anastomosis was occluded or stenosed.

Comment: Survival, incidence of cardiac events, and angiographic patency in the early and late phases are similar for bilateral internal thoracic arteries used either in situ or as Y grafts. However, Y grafting with bilateral internal thoracic arteries increases the number of anastomoses per bilateral thoracic artery, as well as the flexibility of the right internal thoracic artery. ( $\mathrm{J}$ Thorac Cardiovasc Surg 2000;120:990-8)
From the Department of Cardiac Surgery, "G. D'Annunzio" University, Chieti, Italy.

Read at the Eightieth Annual Meeting of The American Association for Thoracic Surgery, Toronto, Ontario, Canada, April 30-May 3, 2000.

Received for publication May 4, 2000; revisions requested June 14, 2000; revisions received June 30, 2000; accepted for publication July 18, 2000.

Address for reprints: Antonio Maria Calafiore, MD, "G. D'Annunzio" University, Department of Cardiac Surgery, S. Camillo de'Lellis Hospital, Via C. Forlanini, 50, 66100 Chieti, Italy (E-mail: calafiore@unich.it).

Copyright () 2000 by The American Association for Thoracic Surgery

$0022-5223 / 2000 \$ 12.00+0 \quad \mathbf{1 2 / 6 / 1 1 0 2 4 9}$

doi:10.1067/mtc.2000.110249 eft internal thoracic artery (ITA) grafting to the left Lanterior descending (LAD) artery is widely recognized to be the most important single determinant for survival and for reduction of late cardiac events in patients who undergo coronary artery bypass grafting. ${ }^{1,2}$ Recently, Pick and associates $^{3}$ showed better long-term outcome in patients in whom bilateral ITAs were used on the left coronary artery system in comparison with patients in whom only the left ITA was used to the LAD. Lytle and associates ${ }^{4}$ also found that having 2 ITAs was advantageous for any patient, regardless of the position of the grafts, and that the advantage was already statistically significant 5 years after the operation. 
In our opinion, a crucial point in bilateral ITA grafting is the proper use of the right ITA. We assume that if this artery is used as a composite graft ${ }^{5}$ (Y graft from the left ITA), the flexibility of the graft increases, as well as the number of anastomoses per patient per bilateral ITA. We analyzed our experience with bilateral ITAs to evaluate whether the long-term clinical and angiographic results were similar if the ITAs were used in situ or as Y grafts.

\section{Patients and methods}

From October 1991 to February 2000, 1818 patients underwent isolated myocardial revascularization with bilateral ITAs in situ ( $n=1378$, group A) or as Y grafts $(n=440$, group $\mathrm{B}$ ). The incidence of $\mathrm{Y}$ grafting was higher in the last part of our experience. The preoperative data are shown in Table I.

Surgical technique. Patients were anesthetized as previously described. ${ }^{5}$ From October 1991 to May 1994, bilateral ITAs were harvested pedicled; since June 1994 the conduits were dissected skeletonized. The pedicled ITA was harvested together with the surrounding veins, muscle, and fascia. The cautery was always used and the side branches were clipped. When the ITA was harvested skeletonized, the surgical technique was as follows. After dissection of the reflection of the mediastinal pleura from the endothoracic fascia, the ITA and both satellite veins were visualized. The fascia was incised medially to the medial thoracic vein for the whole length of the vessel, and it was pulled down on the pleura. A blunt dissection of the artery from the chest wall was performed by means of the tip of the cautery. All the branches were dissected, clipped proximally and distally, and divided with coronary scissors. With this technique, conduits longer than the pedicled ones were obtained; this allowed us to increase the number of sequential anastomoses ${ }^{6}$ and to preserve the sternal vascularization as much as possible. ${ }^{7}$

After heparinization, the ITAs, independently from the harvesting technique used, were distally clipped, injected with $10 \mathrm{~mL}$ of a papaverine solution $(1 \mathrm{mg} / \mathrm{mL})$, and allowed to pharmacologically dilate. ${ }^{5}$

End-to-side anastomosis. If the ITA was harvested as a pedicle, the fascial portion was used. As soon as the fascia was incised, the artery appeared, clean and easy to dissect. If the ITA was harvested skeletonized, the anastomosis was performed laterally, in the left margin of the ITA. The Y graft was always constructed before the start of cardiopulmonary bypass (CPB) or, if $\mathrm{CPB}$ was not used, at the beginning of the operation.

The most suitable point for the anastomosis was chosen. Because the common target vessels for side branches are on the circumflex system, the best point is at the level of the pulmonary artery; for other arrangements, the proximal anastomosis site had to be decided on a case-by-case basis.

The in situ ITA, if pedicled, was prepared at the chosen site
Table I. Preoperative data

\begin{tabular}{llll}
\hline & $\begin{array}{c}\text { Group A } \\
(n=1378)\end{array}$ & $\begin{array}{l}\text { Group B } \\
(n=440)\end{array}$ & P value \\
\hline Age (y) & $61.5 \pm 8.9$ & $62.1 \pm 9.5$ & NS \\
$\quad \geq 75 \mathrm{y}$ & $265(19.2 \%)$ & $102(23.3 \%)$ & $\mathrm{NS}$ \\
Female & $192(13.9 \%)$ & $78(17.8 \%)$ & $\mathrm{NS}$ \\
Ejection fraction (\%) & $59.0 \pm 12.9$ & $55.5 \pm 14.6$ & $<.001$ \\
$\quad \leq 35 \%$ & $76(5.5 \%)$ & $40(9.1 \%)$ & .010 \\
Urgent & $352(25.5 \%)$ & $80(18.3 \%)$ & .002 \\
Left main & $209(15.1 \%)$ & $56(12.8 \%)$ & $\mathrm{NS}$ \\
Two-vessel disease & $345(25.0 \%)$ & $97(22.0 \%)$ & $\mathrm{NS}$ \\
Three-vessel disease & $1033(74.9 \%)$ & $343(77.9 \%)$ & $\mathrm{NS}$ \\
Redo & $37(2.7 \%)$ & $31(7.1)$ & $<.001$ \\
Diabetes & $296(21.5 \%)$ & $133(30.2 \%)$ & $<.001$ \\
\end{tabular}

NS, Not significant.

and then was clamped. A longitudinal incision was performed, 6 to $8 \mathrm{~mm}$ long. The free graft was prepared, opened obliquely at its tip, and then extended to the ITA. A running stitch with an 8-0 Prolene suture (Ethicon, Inc, Somerville, $\mathrm{NJ}$ ), starting from the heel of the free graft, was used. The in situ ITA was unclamped and the proximal anastomosis was carefully checked for any bleeding. After the composite graft was obtained (Fig 1), the procedure, with or without CPB, was begun. Strategically, the inflow conduit was anastomosed first, better to tailor the side branch.

Graft distortion can be avoided merely by placing the ITA over the heart. The inside pressure will keep the graft in the right orientation. As soon as the aorta was unclamped (or, if CPB was not used, when the last anastomosis was completed), a continuous infusion of diltiazem $(5 \mathrm{mg} / \mathrm{h})$ was begun. This infusion was continued up to the first postoperative day, when oral diltiazem was started $(60 \mathrm{mg} 3$ times a day for 4 weeks).

From the operating theater the patients were transferred to the intensive care unit, generally for the first postoperative day, and then to the ward. In the great majority of patients, angiography was performed electively, not because of new ischemic symptoms. No patient had 2 angiograms. The quality of the anastomosis per conduit was graded according to the guidelines of Fitzgibbon and associates. ${ }^{8}$

Follow-up. All the patients were followed up in our outpatient clinic 3, 6, and 12 months after the operation and then every year. We were able to follow up all our patients, directly or by telephone. Survival and survival free from cardiac events (acute myocardial infarction, need of percutaneous transluminal coronary angioplasty, need for reoperation) were considered for our research.

Statistical analysis. Results are expressed as mean \pm SD unless otherwise indicated. Statistical analysis comparing 2 groups was performed with the unpaired 2-tailed $t$ test for the means or $\chi^{2}$ test for categoric variables. Survival and event-free survival curves were obtained with the KaplanMeier method (SPSS software; SPSS, Inc, Chicago, Ill). Statistical significance was calculated with the Mantel-Cox test and z-test. 

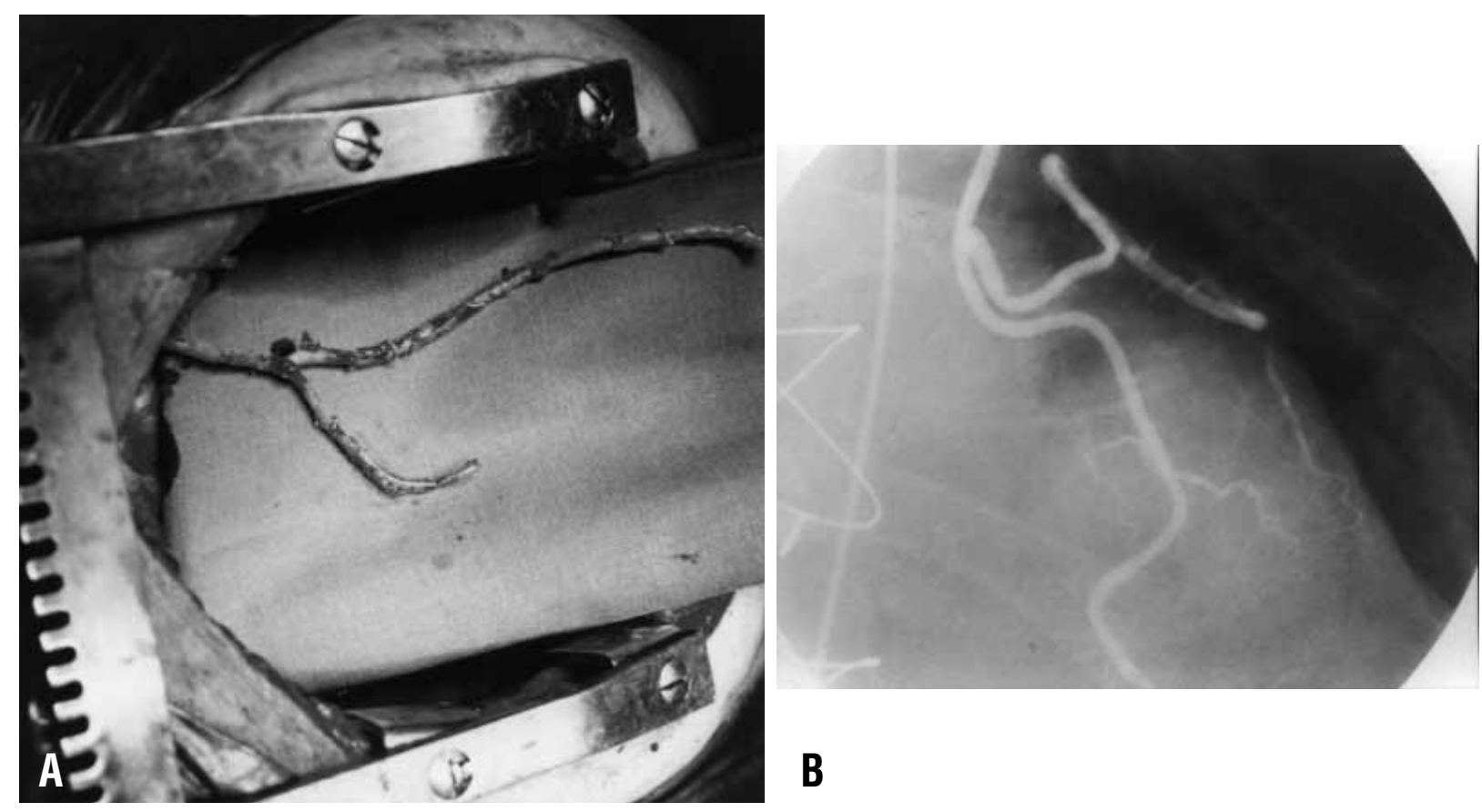

Fig 1. The right ITA was connected to the left ITA with an end-to-side anastomosis (Y graft). A, Intraoperative view; B, postoperative follow-up angiogram.

Table II. Technical details

\begin{tabular}{lccr}
\hline & $\begin{array}{c}\text { Group A } \\
(n=1378)\end{array}$ & $\begin{array}{c}\text { Group B } \\
(n=440)\end{array}$ & P value \\
\hline Anastomoses/patient & $2.9 \pm 0.8$ & $3.1 \pm 0.9$ & .016 \\
Bilateral ITA anastomoses/patient & $2.2 \pm 0.6$ & $2.7 \pm 0.9$ & $<.001$ \\
Left ITA anastomoses/patient & $1.2 \pm 0.5$ & $1.3 \pm 0.5$ & $<.001$ \\
Right ITA anastomoses/patient & $1.0 \pm 0.3$ & $1.4 \pm 0.6$ & $<.001$ \\
TAMR & $1037(75.2 \%)$ & $308(70.3)$ & NS \\
Other conduits & & & \\
$\quad$ RGEA & 276 & 45 & $<.001$ \\
RA & 135 & 8 & $<.001$ \\
IEA & 66 & 6 & .002 \\
$\quad$ SVG & 330 & 136 & .013 \\
\hline
\end{tabular}

ITA, Internal thoracic artery; TAMR, total arterial myocardial revascularization; $R G E A$, right gastroepiploic artery; $R A$, radial artery; IEA, inferior epigastric artery; $S V G$, saphenous vein graft; $N S$, not significant.

\section{Results}

Preoperative data in the 2 groups were not completely similar (Table I), because group B comprised more patients with diabetes or with the need for an urgent or a second operation. Moreover, mean ejection fraction was lower in group B.

$\mathrm{CPB}$ time and crossclamping time were longer in group B $(70.6 \pm 62.9$ minutes vs $62.9 \pm 22.0$ minutes; $P<.001 ; 60.3 \pm 23.0$ minutes vs $52.5 \pm 18.7$ minutes;
Table III. Sequential anastomoses

\begin{tabular}{lllr}
\hline & $\begin{array}{c}\text { Group A } \\
(n=1378)\end{array}$ & $\begin{array}{l}\text { Group B } \\
(n=440)\end{array}$ & P value \\
\hline $\begin{array}{l}\text { Patient with at least 1 } \\
\text { ITA seq anastomosis }\end{array}$ & $314(22.8 \%)$ & $225(51.2 \%)$ & $<.001$ \\
ITA conduit with & & & \\
$\quad$ seq anastomosis & $341(9.7 \%)$ & $277(25.8 \%)$ & $<.001$ \\
With LITA & $284(20.6 \%)$ & $126(28.6 \%)$ & $<.001$ \\
2 distal & 276 & 117 & .004 \\
$>2$ & 8 & 9 & .013 \\
With RITA & $57(4.1 \%)$ & $151(34.3 \%)$ & $<.001$ \\
2 distal & 55 & 125 & $<.001$ \\
$>2$ & 2 & 26 & $<.001$ \\
\hline
\end{tabular}

ITA, Internal thoracic artery; seq, sequential; LITA, left internal thoracic artery; RITA, right internal thoracic artery.

$P<.001$ ). In 257 patients in group A and in 122 patients in group B, CPB was not used.

Technical details are shown in Table II. The number of anastomoses per patient was significantly higher in group B than in group A, as well the number of left and right ITA anastomoses per patient. As a consequence, the number of bilateral ITA anastomoses per patient was higher in group B than in group A, and the difference was statistically highly 
Table IV. Target coronary vessels

\begin{tabular}{rccccc}
\hline & LAD & Diagonal & Cx system & RCA system & Total \\
\hline Group A & & & & \\
LITA & $441(27.9 \%)$ & $135(8.6 \%)$ & $993(63.0 \%)$ & $8(0.5 \%)$ & 1577 \\
RITA & $998(65.0 \%)$ & $58(3.8 \%)$ & $236(15.4 \%)$ & $242(15.8 \%)$ & 1534 \\
Total & $1439(46.2 \%)$ & $193(6.2 \%)$ & $1229(39.5 \%)$ & $250(8.1 \%)$ & 3111 \\
Group B & & & & $3(0.5 \%)$ & 566 \\
LITA & $397(70.1 \%)$ & $122(21.8 \%)$ & $44(7.8 \%)$ & $38(6.1 \%)$ & 625 \\
RITA & $50(8.0 \%)$ & $67(10.7 \%)$ & $470(75.2 \%)$ & $41(3.5 \%)$ & 1191 \\
Total & $447(37.5 \%)$ & $189(15.9 \%)$ & $514(43.1 \%)$ & \\
\hline
\end{tabular}

LAD, Left anterior descending artery; $C x$, circumflex; $R C A$, right coronary artery; LITA, left internal thoracic artery; RITA, right internal thoracic artery.

significant $(2.7 \pm 0.9$ vs $2.2 \pm 0.6 ; P<.001)$. Fewer bilateral ITA graft anastomoses per patient were needed in patients who had in situ pedicled grafts $(2.1 \pm 0.3)$ than in patients with skeletonized $Y$ grafts $(2.8 \pm 1.1 ; P<.0001)$. Table II also shows the conduits that were used to supplement bilateral ITA grafts. A total of 668 patients in group A and 254 in group B had isolated bilateral ITA grafting $(2.3 \pm 0.5$ vs $2.9 \pm 0.9$ anastomoses per patient; $P<0.001$ ); when another conduit was used, the anastomoses per patient rose to $3.5 \pm 0.6$ in group A and $3.6 \pm 0.9$ in group B $(P=$ not significant $[\mathrm{NS}])$.

The number of sequential anastomoses was significantly higher in group B than in group A, in particular with the right ITA (151 vs 57; $P<.001$ ) (Table III).

Total arterial revascularization was achieved in approximately the same percentage of patients the in 2 groups $(75.2 \%$ in group A and $70.3 \%$ in group B; $P=\mathrm{NS})$.

The distribution of distal anastomoses is shown in Table IV and was different in the 2 groups. In group A the right ITA was used more often than the left ITA to graft the LAD (65.0\% vs $27.9 \%$ ); in group B the left ITA was the more common conduit $(70.1 \%$ vs $8.0 \%)$. On the contrary, the circumflex system was revascularized more often with the left ITA in group A $(63.0 \%$ vs $15.4 \%)$ and with the right ITA in group B $(75.2 \%$ vs $7.8 \%$ ). In the right coronary artery system, the right ITA was used less frequently in group B than in group A $(15.8 \%$ vs $6.1 \% ; P<.001)$. The ability to graft the left coronary system (LAD and circumflex) with only bilateral ITAs was different between the 2 groups. In group A $85.6 \%$ of the patients in whom the left coronary system was revascularized had only bilateral ITA grafts, whereas in group B this percentage rose to 94.6\% $(P<.001)$. Moreover, in group A $83.1 \%$ of the anastomoses performed in the left coronary system were done with bilateral ITAs versus $92.4 \%$ in group B $(P<.001)$.
Table V. Postoperative data

\begin{tabular}{lccc}
\hline & $\begin{array}{c}\text { Group A } \\
(n=1378)\end{array}$ & $\begin{array}{c}\text { Group B } \\
(n=440)\end{array}$ & P value \\
\hline Deaths & $28(2.0 \%)$ & $11(2.5 \%)$ & NS \\
Inotropic drugs & $43(3.1 \%)$ & $17(3.8 \%)$ & NS \\
IABP & $9(0.6 \%)$ & $5(1.1 \%)$ & NS \\
AMI & $12(0.9 \%)$ & $5(1.1 \%)$ & NS \\
CVA & $15(1.1 \%)$ & $7(1.6 \%)$ & NS \\
Atrial fibrillation & $181(13.1 \%)$ & $73(16.6 \%)$ & NS \\
Acute respiratory failure & $11(0.8 \%)$ & $7(1.6 \%)$ & NS \\
Acute renal failure & $8(0.6 \%)$ & $4(0.9 \%)$ & NS \\
Bleeding & $551 \pm 441$ & $480 \pm 370$ & .002 \\
Transfused patients & $319(23.1 \%)$ & $120(27.3 \%)$ & NS \\
ICU stay (h) & $22.2 \pm 28.3$ & $18.5 \pm 20.7$ & .011 \\
In-hospital stay (d) & $5.9 \pm 6.3$ & $5.3 \pm 5.0$ & NS \\
\hline
\end{tabular}

$\overline{I A B P}$, Intra-aortic balloon pumping; $A M I$, acute myocardial infarction; $C V A$, cerebrovascular accident; $I C U$, intensive care unit.

Postoperative data are listed in Table V. Thirty-nine patients $(2.1 \%)$ died in the first 30 days after the operation, 28 in group A (2.0\%) and 11 in group B (2.5\%; $P=\mathrm{NS}$ ). All postoperative complications were similar in the 2 groups.

The incidence of hypoperfusion syndrome was similar in the 2 groups (7 [0.5\%] vs 2 [0.45\%]; $P=\mathrm{NS}$ ). When hypoperfusion was suspected, the ITA was always supplemented with a saphenous vein graft. No patient died if the complication was evident in the operating theater, but 3 of 4 died when hypoperfusion became evident in the intensive care unit, although early reoperation was attempted in every case.

Sternal wound healing problems were present in 46 patients $(2.5 \%)$, the incidence being similar in both groups (32 cases in group A [2.3\%] vs 14 cases in group B [3.2\%]; $P=\mathrm{NS}$ ).

Follow-up. Globally, after a mean follow-up of 33.4 \pm 24.7 months, 1737 patients $(95.5 \%)$ were alive and 1727 (94.9\%) were alive without myocardial infarction and surgical or interventional revascularization; the 8- 


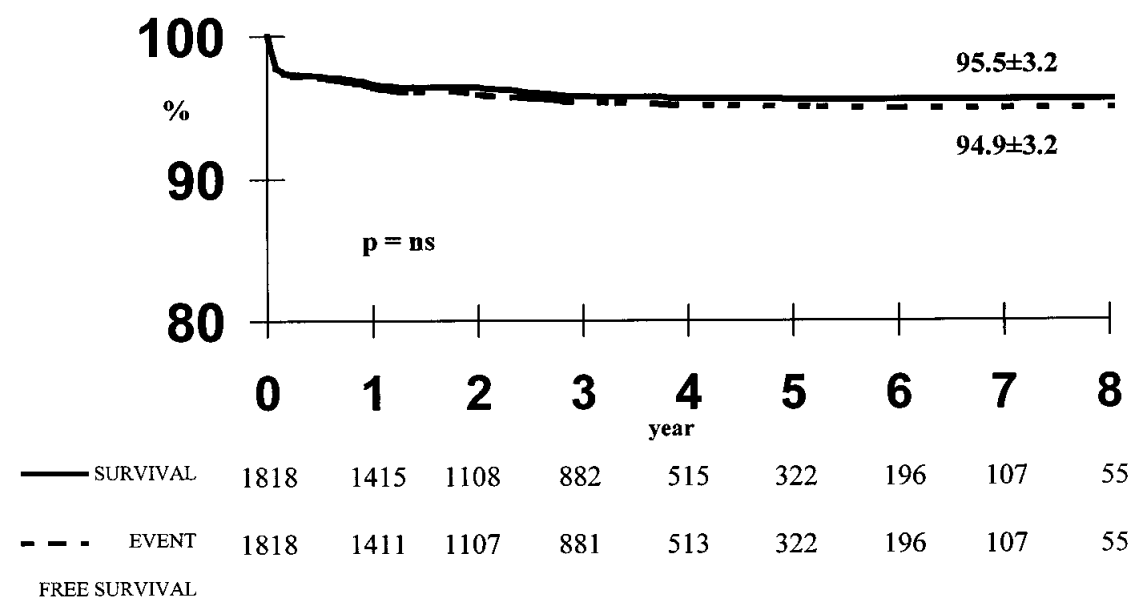

Fig 2. Eight-year survival (solid line) and event-free survival (dashed line) of the global population.

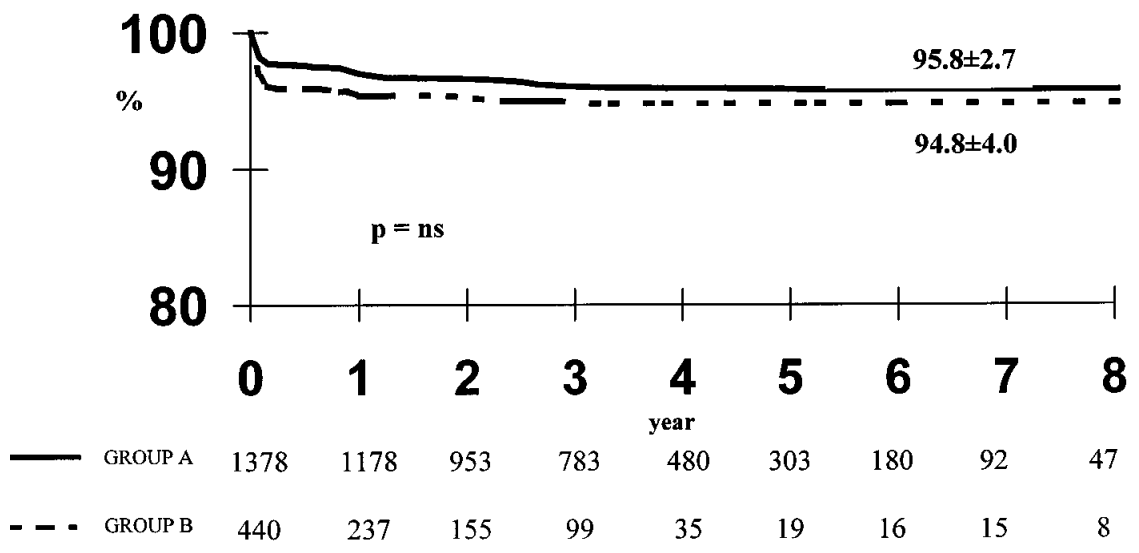

Fig 3. Eight-year survival of group A (solid line) and group B (dashed line).

year survival and event-free survival are shown in Fig 2. Mean follow-up was shorter in group B than in group A $(19.1 \pm 18.8$ months vs $35.5 \pm 23.0$ months; $P<.001)$, because $\mathrm{Y}$ grafts were more prevalent in the more recent experience.

Eight-year survival was $95.8 \% \pm 2.7 \%$ in group A and $94.8 \% \pm 4.0 \%$ in group B $(P=\mathrm{NS})$ (Fig 3); eventfree survival was $95.2 \% \pm 2.9 \%$ in group $\mathrm{A}$ and $93.6 \%$ $\pm 4.4 \%$ in group B ( $P=$ NS) (Fig 4$)$.

After a mean of $17.8 \pm 15.5$ months, 42 patients had died, 23 of cardiac causes (3 acute myocardial infarctions, 18 sudden deaths, 1 right ventricular injury, and 1 after the second redo operation) and 19 of noncardiac causes (11 malignancy, 1 cerebral atrophia, 6 stroke, 1 abdominal aortic aneurysm rupture). Among them, 33 (2.5\%) died in group A and 9 $(2.0 \%)$ in group B $(P=\mathrm{NS})$.
Myocardial infarction occurred in 3 patients in group $A$ and in 1 patient in group B $(P=\mathrm{NS}), 2,12$, and 17 months (group A) and 3 months (group B) after the operation.

Ten patients needed further revascularization after a mean of $31.0 \pm 32.5$ months, 6 in group A ( 3 redo and 3 angioplasty) and 4 in group B (1 redo and 3 angioplasty) $(P=\mathrm{NS})$. The outcome was uneventful; however, 1 of the patients needed a second surgical revascularization and died on the first postoperative day of low output syndrome.

Follow-up angiograms. Early angiograms were obtained in 295 patients (945 anastomoses, 863 distal and 82 proximal Y grafts), 213 (611) in group A and 82 (334) in group B (Table VI). Early and late patency rates were similar in the 2 groups. No Y anastomoses were occluded or stenosed. 


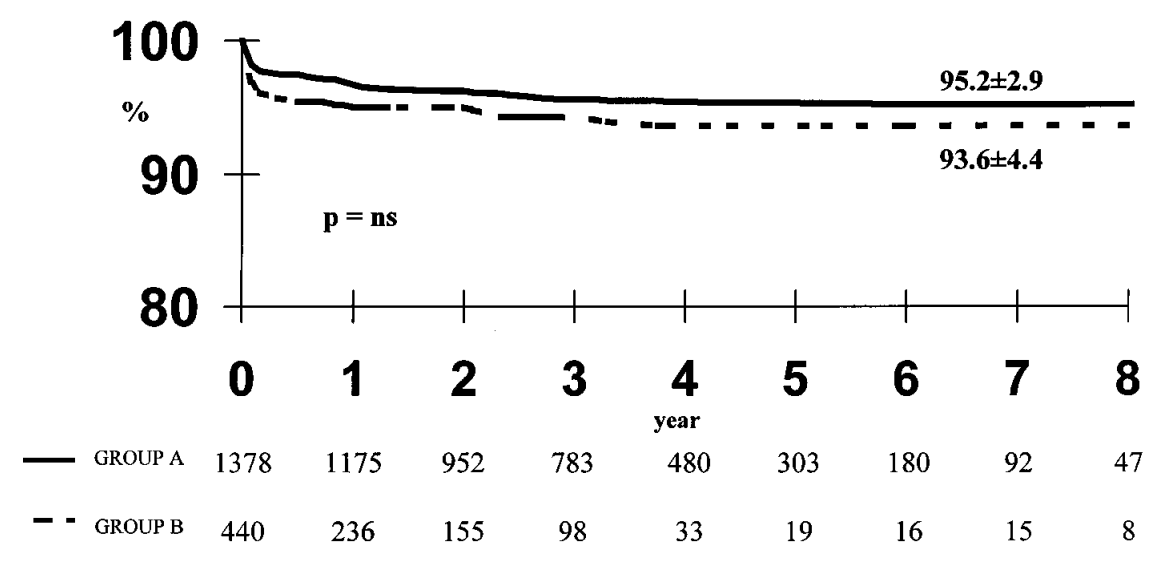

Fig 4. Event-event free survival of group A (solid line) and group B (dashed line).

\section{Discussion}

Bilateral ITA grafting is becoming increasingly popular because it provides satisfying early and late results. Even if past studies did not indicate that long-term outcome was clearly superior to that of single ITA and saphenous vein grafts, ${ }^{9-11}$ more recent reports indicate that bilateral ITA grafting is superior in the very long term. ${ }^{3,4}$

From the technical point of view, whereas the left ITA is generally considered to be the graft of choice for the LAD system, the target vessels of the right ITA remain uncertain. When the right ITA is used in situ, the right coronary artery system is the easiest to reach. However, this strategy was demonstrated to be unsatisfactory because midterm results were not dissimilar to those provided by the saphenous vein graft. ${ }^{12,13} \mathrm{We}$ believe the right ITA is best used as a graft to the LAD or the marginal branches (over or under the aorta); these grafts have to be directed to the left coronary system. ${ }^{2}$ However, sometimes the right ITA is not long enough. In that case the skeletonization technique, described by us and others, ${ }^{7,14-16}$ increases the length and flexibility of the graft; in many instances, this technique is our first choice.

Tector and coworkers ${ }^{17}$ described the possibility of achieving complete revascularization by using bilateral ITAs as $\mathrm{T}$ grafts. The composite graft technique, as a $\mathrm{T}$ or a $\mathrm{Y}^{5,18}$ from the left ITA, was also reported for grafts different from the right ITA (radial artery or epigastric artery), with excellent early and midterm results. This technique allows the extensive use of bilateral ITA grafts to the left coronary system, as well as to the right coronary artery system, if necessary. However, longterm results are lacking, because some concern exists regarding the ability of a single ITA to support the
Table VI. Postoperative follow-up angiograms

\begin{tabular}{|c|c|c|c|}
\hline \multirow[b]{2}{*}{ Grade } & \multicolumn{3}{|c|}{ Early $(13.3 \pm 9.4$ days $)$} \\
\hline & $\begin{array}{c}\text { Group } A \\
\text { (611 anast/213 pts) }\end{array}$ & $\begin{array}{c}\text { Group B } \\
\text { (334 anast/82 pts) }\end{array}$ & $\mathrm{P}$ value \\
\hline A & $594(97.2 \%)$ & $322(96.4 \%)$ & NS \\
\hline B & $10(1.6 \%)$ & $2(0.6 \%)$ & NS \\
\hline \multirow[t]{3}{*}{0} & $7(1.2 \%)$ & $10(3.0 \%)$ & NS \\
\hline & \multicolumn{3}{|c|}{ Late $(17.5 \pm 18.4 \mathrm{mo}, 6-84)$} \\
\hline & $\begin{array}{c}\text { Group A } \\
\text { (72 anast } / 25 \mathrm{pts} \text { ) }\end{array}$ & $\begin{array}{c}\text { Group B } \\
\text { (264 anast/63 pts) }\end{array}$ & $\mathrm{P}$ value \\
\hline A & $71(98.6 \%)$ & $261(98.8 \%)$ & NS \\
\hline B & $1(1.4 \%)$ & $1(0.4 \%)$ & NS \\
\hline 0 & - & $2(0.8 \%)$ & NS \\
\hline
\end{tabular}

Anast, Anastomoses; pts, patients.

whole coronary circulation. The intermediate anastomosis may be the source of some problems, impairing the perfusion of the circumflex system.

We compared our long-term results in patients having in situ bilateral ITA grafts with those of patients having bilateral ITA Y grafts. Technically, the Y graft group had more bilateral ITA anastomoses, mainly in the left coronary system. The number of right ITA anastomoses per patient rose from 1.0 to 1.4 (Table II), and the number of sequential anastomoses per patient and per conduit rose as well. The right ITA again showed the highest increase (Table III). The early clinical and angiographic results showed no difference between the groups, and the late results were also similar.

Our data show that, 8 years after surgery, the use of bilateral ITAs as $\mathrm{Y}$ grafts provides excellent results, 
comparable with those of in situ bilateral ITA grafts. The flexibility of the right ITA is increased and allows extended grafting to the left coronary system.

\section{REFERENCES}

1. Loop FD, Lytle BW, Cosgrove DM, Stewart RW, Goormastic M, Williams GW, et al. Influence of the internal mammary artery graft on 10-year survival and other cardiac events. N Engl J Med 1986;314:1-6.

2. Cameron A, Davis KB, Green G, Schaff HV. Coronary bypass surgery with internal-thoracic-artery grafts-effects on survival over a 15-year period. N Eng1 J Med 1996;334:216-9.

3. Pick AW, Orszulak TA, Anderson BJ, Schaff HV. Single versus bilateral internal mammary artery grafts: 10-year outcome analysis. Ann Thorac Surg 1997;64:599-605.

4. Lytle BW, Blackstone EH, Loop FD, Houghtaling PL, Arnold JH, Akhrass R, et al. Two internal thoracic arteries are better than one. J Thorac Cardiovasc Surg 1999;117:855-72.

5. Calafiore AM, Di Giammarco G, Luciani N, Maddestra N, Di Nardo E, Angelini R. Composite arterial conduits for a wider arterial myocardial revascularization. Ann Thorac Surg 1994; 58:185-90.

6. Calafiore AM, Vitolla G, Iacò AL, Fino C, Di Giammarco G, Marchesani $\mathrm{F}$, et al. Bilateral internal mammary artery grafting: midterm results of pedicled versus skeletonized conduits. Ann Thorac Surg 1999;67:1637-42.

7. De Jesus RA, Acland RD. Anatomic study of the collateral supply of the sternum. Ann Thorac Surg 1995;59:163-8.

8. Fitzgibbon GM, Kafka HP, Leach AJ, Keon WJ, Hooper GD, Burton JR. Coronary bypass graft fate and patient outcome: angiographic follow-up of 5,065 grafts related to survival and reoperation in 1,388 patients during 25 years. J Am Coll Cardiol 1996;28:616-26.

9. Berreklouw E, Schönberger JPAM, Bavink JH, Verwaal VJ, Koldewijn EL, van der Tweel I, et al. Similar hospital morbidity with the use of one or two internal mammary arteries. Ann Thorac Surg 1994;57:1564-72.

10. Galbut DL, Traad EA, Dorman MJ, DeWitt PL, Larsen PB, Kurlansky PA, et al. Seventeen-year experience with bilateral internal mammary artery grafts. Ann Thorac Surg 1990;49:195201.

11. Fiore AC, Naunheim KS, Dean P, Kaiser GC, Pennington DG, Willman VL, et al. Results of internal thoracic artery grafting over 15 years: single versus double grafts. Ann Thorac Surg 1990;49:202-9.

12. Carrell T, Horber P, Turina MI. Operation for two-vessel coronary artery disease: midterm results of bilateral ITA grafting versus unilateral ITA and saphenous vein grafting. Ann Thorac Surg 1996;62:1289-94.

13. Dion R, Verheist R, Rousseau M, Goenen M, Ponlot R, KestensServage Y, et al. Sequential mammary grafting: clinical, functional and angiographic assessment 6 months postoperatively in 231 consecutive patients. J Thorac Cardiovasc Surg 1989;98:809.

14. Bical O, Braunberger E, Fischer M, Robinault J, Fairet JC, Frames $\mathrm{Y}$, et al. Bilateral skeletonized mammary artery grafting: experience with 560 consecutive patients. Eur J Cardiothorac Surg 1996;10:971-6.

15. Sauvage LR. Extensive myocardial revascularization using only internal thoracic arteries for grafting the anterior descending, cir- cumflex and right system. In: Myers WO, editor. Cardiac surgery. Philadelphia: Hanley \& Belfus; 1992. p. 397-419.

16. Parish MA, Asai T, Grossi EA, Esposito R, Galloway AC, Colvin $\mathrm{SB}$, et al. The effects of different techniques of internal mammary artery harvesting on sternal blood flow. J Thorac Cardiovasc Surg 1992;104:1303-7.

17. Tector AJ, Amundsen S, Schmahl TM, Kress DC, Peter M. Total revascularization with T-grafts. Ann Thorac Surg 1994;57:8-9.

18. Royse AG, Royse KL, Yu G. Blood flow in composite arterial grafts and effect of native coronary flow. Ann Thorac Surg 1999;68:1619-22.

\section{Discussion}

Dr Alfred J. Tector (Milwaukee, Wis). I congratulate Dr Calafiore and his associates for the superb results with bilateral ITA grafting. Since it has been shown that grafting the attached left ITA to the LAD significantly improves longterm survival and outcomes of coronary artery bypass graft operations, a few publications have demonstrated further increase in survival when bilateral ITAs were used. Dr Calafiore's report is obviously one of these.

The 8-year survival, freedom from reintervention, and low incidence of postoperative myocardial infarction in the 1818 patients who received bilateral ITA grafts definitely surpasses the results reported for patients with single left ITA grafts and saphenous vein grafts. However, the average left ventricular ejection fraction in this series was more than 55\%, and fewer than $10 \%$ of the patients had an ejection fraction of less than $35 \%$. The average age was younger than 62 years, $15 \%$ had left main coronary artery disease, and fewer than $7 \%$ were undergoing reoperations. Early patency in 295 patients and later patency in 88 patients were about $98 \%$.

Another important finding in this group is that survival and patency are similar in patients who received attached bilateral ITAs versus those who had the free right ITA anastomosed to the attached left ITA. Besides allowing for a more sequential anastomosis, the free right ITA is not passing over or under the ascending aorta and is not in the way if reoperation becomes necessary in the future. This information is encouraging for those of us who are attempting to bypass as many coronary arteries as possible with ITA grafts.

The number of patients with 2- and 3-vessel diseases were not mentioned in the manuscript. Only 291 anastomoses were constructed to the right coronary artery with ITA grafts, whereas 1886, 382, and 1743 LAD, diagonal, and circumflex anastomoses were made.

I have 2 questions for Dr Calafiore. What types of conduit were used for the $28 \%$ of the anastomoses that were not constructed with ITA grafts, and what was their patency? How did you determine when to use an ITA graft and when to select another conduit?

Dr Calafiore. Thank you very much, Dr Tector. A certain number of the patients having ITA grafts also had a saphenous vein graft, radial artery, inferior epigastric artery, or gastroepiploic artery graft. The patency rate was different.

The patency rate of the saphenous vein graft was $75 \%$. It was not reported in the article because the target of the 
research was the ITA. The patency rates with the gastroepiploic $(86.5 \%)$ and radial artery grafts $(95 \%)$ were higher than for saphenous vein grafts. Basically, we found, as Professor Dion has reported, that the long-term patency rate of saphenous veins is satisfying.

I agree with Dr Tector that the surgical population in Italy is somewhat different from the population in the United States. Our cardiologists are less aggressive than American cardiologists. For this reason, we see many patients with 3vessel disease who had no previous interventional cardiology. The mean ejection fraction in our patients perhaps is higher than the mean ejection fraction in the American surgical experiences. However, the concept that this article emphasizes is that the use of the bilateral ITA graft, at least in a population like ours in Italy, gives good long-term results, and both technical solutions (the in situ or Y graft) can be used satisfactorily.

Finally, Dr Tector underlined an important point. The Y graft technique, when indicated, leaves the ascending aorta completely free, reducing the risk of a resternotomy in case of repeat revascularization or valve surgery.

Dr Guo-Wei He (Hong Kong, China). I have 3 questions: First, are the target vessels for the right ITA the same for in situ grafts as for part of a Y graft? Second, is the patency for the right ITA the same as that for the left ITA? This has been a major disagreement in other studies.

My final question is the major question. Since your results with the 2 different methods are very similar, which do you prefer in the current clinical setting? What are your indications for using bilateral ITAs as in situ grafts and as Y grafts?

Dr Calafiore. In our strategy we prefer to use both ITAs on the left side of the heart. Therefore, if the patient needs 4 or 5 grafts on the left side, we prefer the Y graft. If the patient is young, we prefer the $\mathrm{Y}$ graft, because it does not interfere with future aortic or mitral valve surgery. Leaving the grafts on the left side of the heart, away from the midline, will reduce the risk of future operations.

We prefer, if possible, not to use the right ITA in the right coronary artery, because some other reports have shown similar long-term patency for right ITA and saphenous vein grafts.

To answer your second question, in our experience the right ITA had a patency rate similar to that of the left ITA.

In response to your third question, we now are increasingly using Y grafts because this technique allows us to perform more anastomoses with the ITAs, reducing the need for a third graft, either saphenous vein or arterial. Our strategy is focused more on $\mathrm{Y}$ grafting than on in situ grafting.

Dr Robert A. Dion (Leiden, The Netherlands). I congratulate Dr Calafiore for his excellent results, and I would like to offer some additional support for his strategy.

In our early experience with arterial revascularization, we anastomosed the pedicled right ITA to the distal right coronary artery. Our 6-month patency rates were only $80 \%$. After the reports of Dr Tector and Dr Calafiore, we have increasingly used Y ITA grafts for grafting the distal right coronary artery branches, and our patency rates are now not different from those obtained with pedicled ITA grafts to the left coronary system.

Dr Calafiore. Thank you very much.

Dr Paul Kerr (Buffalo, NY). I want to echo what was asked previously: In the patients in whom you used the pedicled right ITA, where on the right coronary artery were you able to make the anastomosis? Being able to graft more distally on the right coronary artery may be one of the advantages to using this as a $\mathrm{Y}$ graft.

Did you find that you were able to graft distally enough with a pedicled graft, or were you using your Y grafts to graft the posterior descending artery or the posterolateral ventricular branch?

Dr Calafiore. We usually do not use a pedicled ITA graft, as our preference is now to use a skeletonized graft. This strategy gives us the advantage of having a very long graft, especially in the $\mathrm{Y}$ configuration. For this reason, we are sometimes able to graft the distal right coronary artery coming from the left side.

When we used the pedicled right ITA, it was very difficult to reach a suitable anastomotic site on the right coronary artery, as this artery is often diseased or calcified. We prefer to graft to the posterior descending artery, which often is of good quality; this limits the use of the right ITA, at least in situ.

Dr Joseph M. Craver (Atlanta, Ga). My question relates to patients with diabetes, particularly the insulin-dependent younger patients and the older patients with adult-onset diabetes. We are seeing a significantly increased number of such patients, not only because of the aging population in general, but also because interventional cardiologists are having unsatisfactory results in patients with diabetes, particularly with multivessel disease, and are referring them for surgical therapy.

With bilateral ITA harvesting, particularly if the pedicled techniques are used, we find that wound healing is a significant problem, either ischemic nonhealing or increased incidence of infection. What is your experience with that? Can you offer us any help?

Dr Calafiore. In our experience, sternal wound healing problems were significantly more prevalent with pedicled ITAs than with a single ITA. In 1994 we started skeletonizing the ITAs, and this changed our results. Because harvesting the ITA in a skeletonized fashion reduces sternal devascularization, there was a huge reduction in the incidence of sternal wound problems in patients with diabetes.

Today we are using 2 ITAs in every patient who needs this strategy, independently from obesity, chronic obstructive pulmonary disease, or diabetes. The incidence of sternal wound healing problems, also in this group of high-risk patients, is similar when a single ITA is used, supplemented by saphenous vein grafts or other arterial conduits, or when bilateral ITAs are used.

Dr D. Craig Miller (Stanford, Calif). What about female gender? It used to be a risk factor with bilateral ITA grafting.

Dr Calafiore. So long as the ITAs are skeletonized, gender is not a risk factor. 
Dr Robert D. Moses (Boston, Mass). I routinely perform a left ITA graft and radial artery $\mathrm{Y}$ graft off the ITA, and the vast majority of patients are weaned from $\mathrm{CPB}$ without any trouble. Recently, I performed a Y graft in a patient who had ischemia in the circumflex distribution preoperatively and required intra-aortic balloon support. While he was being weaned from CPB, he had major ST changes in the lateral distribution associated with mitral regurgitation. I reinstituted $\mathrm{CPB}$, detached the radial artery graft from the ITA, and found that it was widely probe-patent and flushed well. To ensure inflow, I lengthened the radial artery graft with a saphenous vein interposition graft coming off the aorta.

While CPB was being terminated again, there was still extensive ischemia in the lateral distribution with balloon support. The ischemia gradually resolved, the patient did not show signs of a myocardial infarction, and he did quite well. This case would appear to represent acute flow insufficiency in the radial artery graft. What has your experience been with acute flow insufficiency in arterial grafts, and how do you manage the problem?

Dr Calafiore. I think that this patient had some kind of flow insufficiency in the circumflex territory. However, if a patient has acute ischemia during or before the operation, often the distal resistances are very high in the target territory, and this problem is not related to any kind of graft you can use. As resistances will lower with time, the global situation has a tendency to improve. In this particular situation, supplementation with the saphenous vein very likely did not help.

We have encountered hypoperfusion in a few patients. It is difficult to understand hypoperfusion, because often it is a technical problem. In all these cases we prefer to double the target territory (or territories) with a saphenous vein graft from the aorta, and often that helps. In your case, perhaps the problem was not true hypoperfusion but pre-existing acute ischemia in the grafted territory.

Dr G. Hossein Almassi (Milwaukee, Wis). My question is related to the fact that now we are putting all our eggs in one basket, depending on flow from the left ITA for revascularization of the entire myocardium. In one of your slides, resting flow appeared to be very low. Do you have a flow measurement below which you abandon the Y graft in favor of other alternatives, such as free ITA, right ITA, free off the aorta or saphenous vein, or other grafts? How do you decide to commit yourself to a $\mathrm{T}$ or $\mathrm{Y}$ graft for revascularization of the entire heart?

Dr Calafiore. Personally, I do not worry about the amount of flow we can measure in the graft, because the determinant of the flow depends on many variables, such as the degree of the proximal stenosis, the quality of the territory, and the length of the graft. What is really important is the shape of the curve, indicating diastolic perfusion.

Since the basal flow value often has little meaning, we are trying to detect in the operating room the increase of the basal flow after a pharmacologic test. This finding will be correlated with postoperative angiograms and will give us more information about the quality of the anastomosis.

To answer your question, we do not have a minimum value. Of course, if flow through the $\mathrm{Y}$ graft is only $3 \mathrm{~mL} / \mathrm{min}$, very likely this graft is not working properly, but this is an extreme situation.

\section{Timely}

The Journal of Thoracic and Cardiovascular Surgery delivers the information you need now. Articles usually appear within four months of acceptance. 